\title{
Experimental Validation to a Prototype Magnetorheological (MR) Semi-Active Damper for C-Class Vehicle
}

\author{
H. Unuh, P. Muhamad * F. Yakub, M. A. Ismail and Z. Tanasta \\ Intelligent Dynamics and System Research Laboratory, \\ Malaysia-Japan International Institute of Technology, Universiti Teknologi Malaysia, \\ 54100 Kuala Lumpur, Malaysia \\ *Email: pauziah.kl@utm.my
}

\begin{abstract}
In this study, a semi-active damper with OEM technical standard featuring MR fluid was fabricated to assess its use as potential reinforcement in enhancing c-class vehicle ride comfort. The finite element modelling was employed to investigate the capability of the MR semi-active damper prototype design in altered the damping utilizing unique rheological properties of MR fluid. The quarter car test rig completes with DYTRAN accelerometer and LMS Scadas mobile was operated to measure the RMS sprung mass acceleration of the MR semi-active damper prototype caused by a $5 \mathrm{~cm}$ sinusoidal bump at speed of $10 \mathrm{~km} / \mathrm{h}$. The finite element modelling gave the best representation of the ability of the design to manifest the shear stress development of MR fluid used. Indeed, the MR semi-active damper model prototype was able to enhance ride comfort by decreasing the acceleration of sprung mass compare to OEM passive damper. It was found that the applied current had the greatest influence on RMS sprung mass acceleration when measured over a range of frequency.
\end{abstract}

Keywords: MR damper; semi-active damper; MR fluid; finite element modelling; real working environment.

\section{INTRODUCTION}

Ever since the vehicle was invented and perfected in Germany and France in the late 1800 s, vibration impact from the road profile is a two blades knife for ride comfort and drivability achieved at the same time. Fundamentally, the existing vehicle suspension system remains very crude even though went a very long development until now. The suspension system is typically consisting of steel springs and dampers. During the movement of a vehicle, steel spring responsible to sustain the tyre in a helpful geometry with road profile. In the event of roads get even worse, the damper is in charge to prohibit the spring from persistently oscillating once they have been deflected. For that reason, the ability of the tyre to resist the deflection is very dependent on the spring rate and damping rate. As the vehicle moving on the smooth roads, a suspension system with a relatively stiff and highly damped system is recommended. Yet, such an approach is bottom-out for a vehicle that dealing with bumpy roads. Thus, there are frequent tradeoffs in the suspension system to serves in the finest condition.

In an extensive range of time, the active suspension system was once seen as the answer until their development slowly crawl because of its need of hefty power source that directly raised the concern of the fail-safe requirement [1]. In the first months 1980s, a semi-active suspension system that work predominantly adjusting the structural 
damping and effective as active suspension system was proposed. The earliest approach of the semi-active suspension system is through orifice design modifying. The flow velocity of oil in the damper can be adjusted but indirectly causes an increase to the timesettling [2]. Numerous approaches have been suggested to optimise the semi-active suspension system including the use of smart material technology.

Smart material technology has an insightful impact on the evolution of suspension system due to their adaptation attributes to the environmental system generally. In the semi-active suspension system, the adaptation and the ability to respond to change are fascinating and crucial for regulating the trade-off between drivability and ride comfort. Magnetorheological (MR) damper, therefore, can be defined as a damper that has the capability of providing an active response to alter their behaviour according to the road and driving style [3]. Regarding the definition, the terminology of magnetorheological (MR) is used such that the smart material of MR fluid is utilised. MR fluid is the material that exhibits fast, alterable and tuneable dramatic changes from continuous steady-state to the highly viscous state upon the magnetic field is applied [4]. Over the last decades, there is a large volume of published studies in understanding its phenomena in the broad applications that use these field-controllable materials for commercialization [4-12].

A considerable amount of literature has been published on design optimization and development of the MR damper. Preliminary work on optimal MR damper design was undertaken by Gavin et al. (2001). It has been demonstrated that a low current supply of their optimal design able to grant a large force up to $4 \mathrm{kN}$ [13]. In 2007, Nguyen and co-workers published a paper in which they described various geometric dimensions optimization of MR valve via finite element analysis [14]. The study of the MR damper optimal design for the vehicle was first carried out by Nguyen and Choi two years later using the same method. In their analysis of damping force and dynamic range, the maximum yield stress established by the optimal design validated the design configuration. [15]. Ferdaus and his co-researchers (2014) claims that their configuration consist of single-stage coil and chamfered piston at both ends is far more effective in providing maximum force compare to another 44 models configuration [16]. A broader method has been adopted by Mangal and Kumar (2015) whose develop an optimal MR damper model using finite element method hybrid with Taguchi method and experimental validation. They reported that working clearance between piston and cylinder contributes to the highest effect on optimization. The results are confirmed using experimentation where a very small difference was found [17]. Most of the recent studies in the field of MR damper for vehicle suspension system have only focused on simulation. Even though there are very few papers focus on geometry optimization, researchers have not treated technical standard dimension in much detail in their study.

One of the biggest challenges in developing semi-active damper based on MR fluid is establishing an accurate model to effectively take advantage of the superior rheological properties of MR fluid. Indeed, at present, research in designing MR damper considering technical standards is still infancy. Furthermore, as far as the writers are aware, there are very few works carried out on the effectiveness of the MR damper for use in a real working environment that easily subjected to parameter uncertainties and external disturbance in practice [18-20]. However, at present, only Miao Yu et al. carried out an experiment on a real road for vehicle application [21]. Therefore, it is sensible to design MR damper considering vehicle technical standards and real working environment in order to improve its performance in realising the full potential of MR fluid. This work aims to fabricate MR damper with original equipment manufacturer (OEM) standards for 
c-class vehicle and the effectiveness is tested physically for suitability compromising the drivability and ride comfort trade-off in the real working environment.

\section{METHODOLOGY}

It was decided that the best method to adopt in this research was to established precision drawings and technical illustration of the damper using three-dimensional computeraided design (CAD) package in SolidWorks software based on OEM standardization for the c-class vehicle and the synthesis of magnetic flux density in the damper was done utilizing finite element method in ANSYS Mechanical APDL 15.0 software before being tested in real working environment.

\section{The Magnetorheological (MR) Semi-Active Damper Prototype}

The MR semi-active damper prototype provides an improvement based on the original equipment manufacturer (OEM) damper standard dimension (see Table 1) with a straightforward construction and lower manufacturing cost. The main feature of the innovation is the involvement of magnetorheological (MR) fluid which can alter its shear stress characteristic within milliseconds under the influence of magnetic induction. The typical MR damper is usually in monotube design which coil is integrated with the piston of the damper. In response to the force applied, the monotube approach obliges the piston to travel only within a fixed distance of a cylindrical reservoir [22-24]. The electrical wire connected passing through the channel in the piston rod which is created using perforation techniques. This approach caused the wire to flex as it is experiencing continuous movement as the piston gives a response to any vertical direction force. In the long run, it results in breakage of the wire causing no magnetic flux can be induced to react with MR fluid. In addition, some problems may occur such as introduction to the channel may decrease the strength of the damper generally, the piston rod specifically to sustain and be tolerant to a larger load. Hence, the prototype promotes the use of twintube.

Table 1. Geometry standard dimension of the OEM damper for C-Class vehicle.

\begin{tabular}{lc}
\hline Part/Assembly & Dimension $(\mathrm{mm})$ \\
\hline External housing outer diameter & 39.00 \\
External housing inner diameter & 36.63 \\
External housing height & 342.29 \\
Internal housing outer diameter & 27.42 \\
Internal housing inner diameter & 24.82 \\
Internal housing height & 288.01 \\
Piston head height & 24.96 \\
Stroke distance & 299.52 \\
\hline
\end{tabular}

Referring to Figure 1, a piston assembly is disposed in the inner cylinder and has an outer cylinder as protection for the prototype damper's inner part. The coil with the size of AWG24 is held at stationary with respect to one of the housings which is the inner cylinder to increase the dependability of the electrical connection to the coil and solve the strength problem. The coils were capped with polyimide film to prevent direct interaction with MR fluid as well as medium to endure high-temperature causes during damper 
operation. Additionally, there is air gap of $3 \mathrm{~mm}$ in an attempt to minimize the heat generated. It also acts as a valve control for a flow passage between the inner and outer cylinder and capable of generating a magnetic field across at least a portion of the flow gap. A pair of ferromagnetic rings is provided for directing the magnetic field or flux through the flow gap.

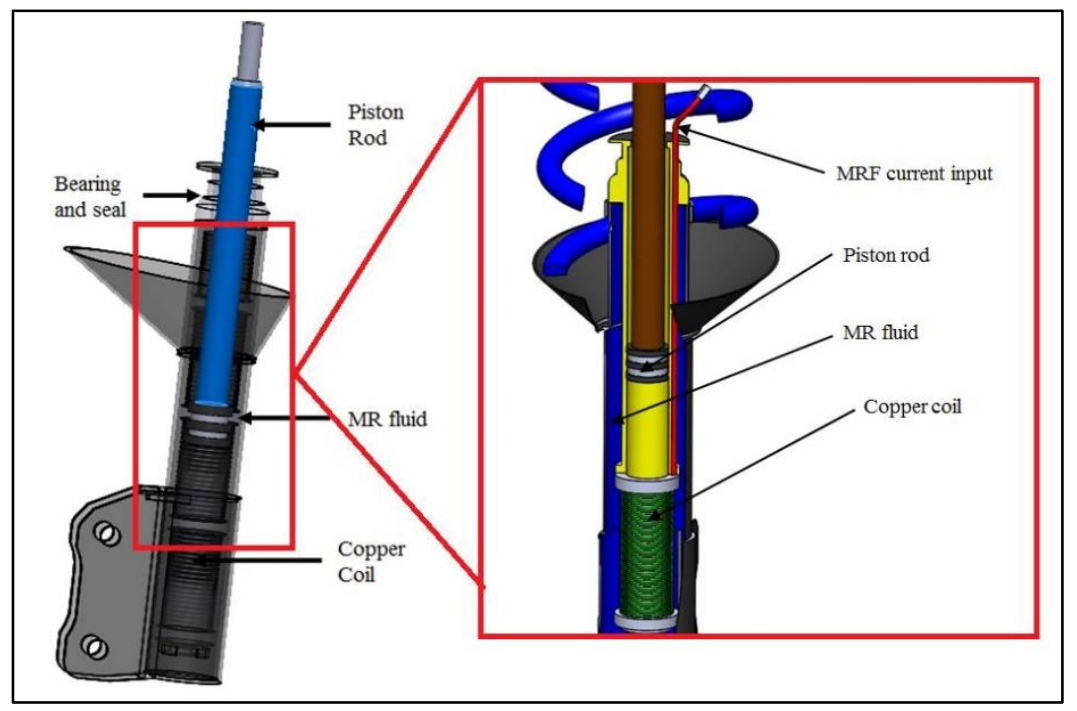

Figure 1. Conceptual design drawing of the MR semi-active damper prototype.

\section{Finite Element Modelling}

The 2-D axisymmetric model of the control valve in the MR semi-active damper prototype is analysed using the finite element method. The goal of this approach is to determine the magnetic flux generated with given current and as pioneer evidence that the design damper can fulfil the main requirement of utilising the MR fluids. Schematic representation of the 2-D axisymmetric model of the MR control valve of design is shown in Figure 2.

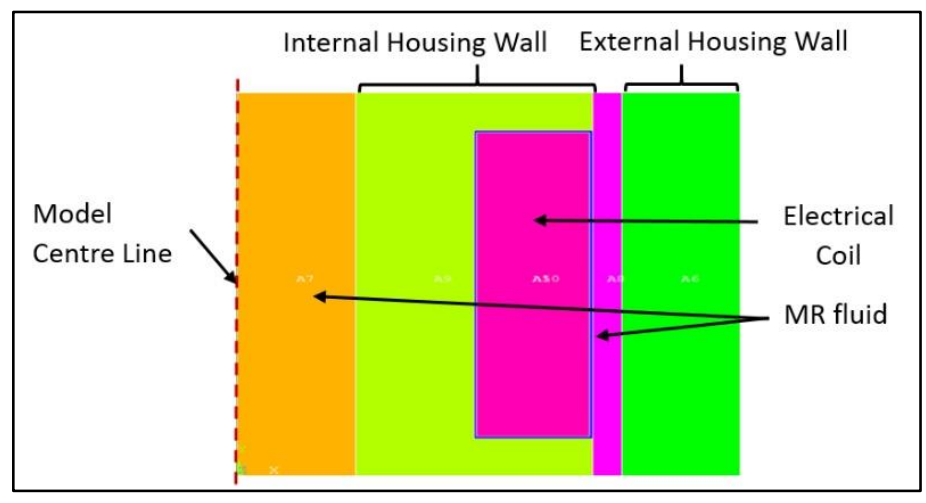

Figure 2. A 2-D axisymmetric model of MR control valve.

The analysis is simplified to a single iteration analysis. Outside of the model parameter is presumed not experiencing any flux leakage and saturation of the material does not ensue. The ramification of flux leakage is demonstrated by creating a layer of air bordering the iron. The maximum radius of the iron shall be equal to or smaller than 
the air layer. ANSYS Mechanical APDL version 15.0 obliges the user to insert the input in the form of current density for electromagnetic nodal analysis. The current density is defined as:

$$
J S=N I / A
$$

where $\mathrm{N}$ is the number of turns, I the current input and $\mathrm{A}$ is the coil area. The number of turns used for the finite element modelling is 450 turns. The current is ranging from $0.2 \mathrm{~A}$ to $2.0 \mathrm{~A}$ while the coil area is $1.4253 \times 10^{-3} \mathrm{~m}^{2}$. The flux work parallel to the surface of the model parameter in congruence with the assumption. The model is surrounded with the flux parallel boundary condition. A Maxwell stress tensor and a virtual work computation employed to recapitulate the forces generated in the model.

Each material in the model is defined under the option of constant relative permeability. Table 2 shows the properties of the material involved in the model. However, ANSYS material library does not contain any data for MR fluid. Thus, the properties are specified using the B-H curves graph shown in Figure 3.

Table 2. Properties of material.

\begin{tabular}{lc}
\hline Model Area & Constant Relative Permeability \\
\hline Internal housing wall & 75 \\
External housing wall & 75 \\
MR fluid & B-H curve \\
Coil element & 1 \\
Air gap & 0.005 \\
\hline
\end{tabular}

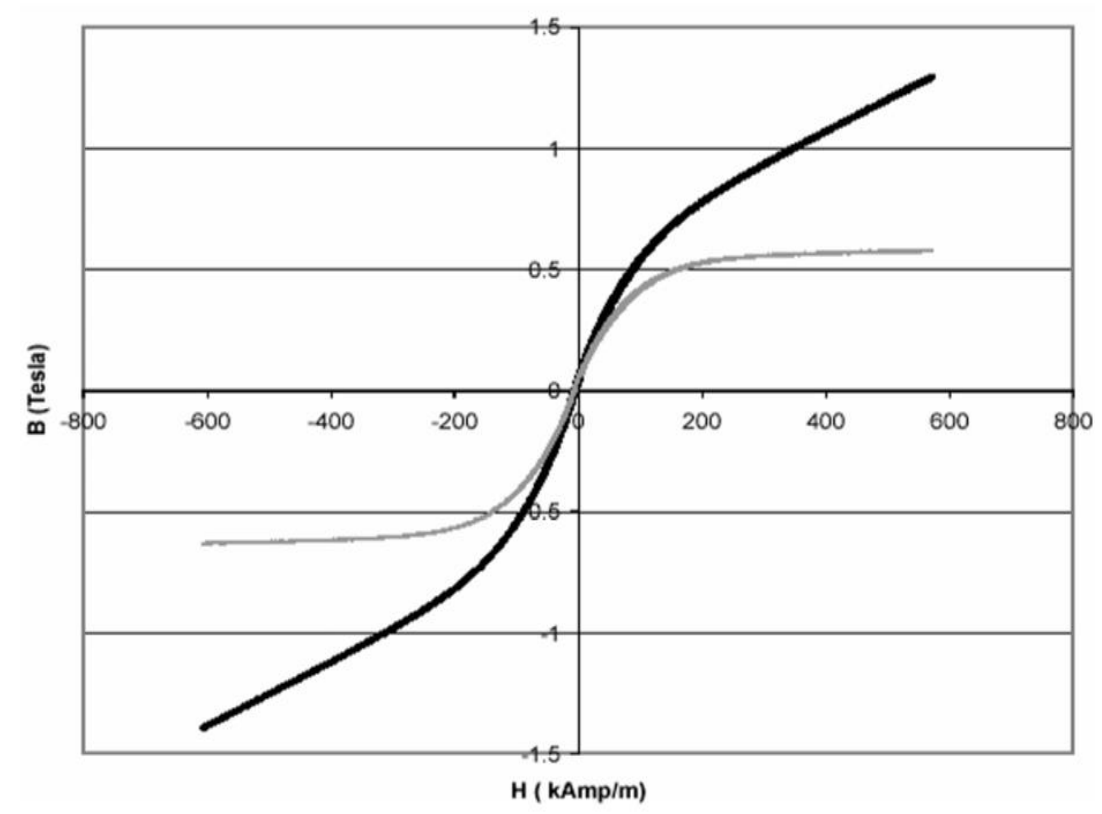

Figure 3. Magnetorheological (MR) fluid B-H curve (Copyright, LORD Corporation) [25]. 


\section{The Realisation of the Quarter Car Test Rig and Real Working Environment}

A quarter car test rig in Figure 4 is designed and constructed to study and analyse the effect of real road profile on the ability of the MR semi-active damper prototype promoting ride comfort to the passenger. In order to evaluate the effectiveness of the MR semi-active damper prototype, the quarter car test rig is realising to compatible with OEM passive damper and as well the MR semi-active damper prototype. The most vital embodiment in the quarter car test rig is the variable stiffness mechanism where it consists of suspension system complete with damper and steel spring with an attachment point to the sprung mass at the upper end and interlocks with the tyre at the lower arm. The main feature of the quarter car test rig is able to replicate the dynamic behaviour of the c-class vehicle. Nonlinearities, damping and resonance frequencies is essential to be analogous. In addition, the quarter car test rig shall ideally direct the perpendicular motion of the chassis in response to excitation with amplitudes of $5 \mathrm{~cm}$ within the $25 \mathrm{~Hz}$ frequency.

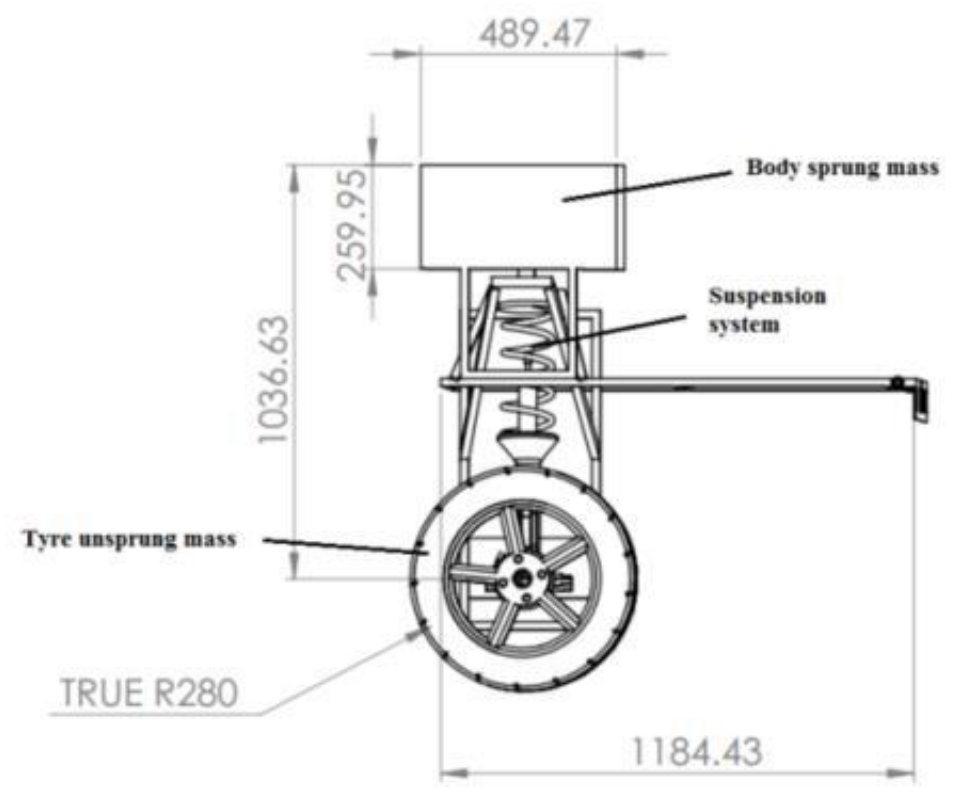

Figure 4. Technical drawing of the quarter car test rig.

The quarter car test rig is dragged behind a vehicle with a constant velocity of 10 $\mathrm{km} / \mathrm{h}$ on a real road surface profile. A sinusoidal bump with an elevation of $5 \mathrm{~cm}$ at a distance of exactly $10 \mathrm{~m}$ to ensure the speed of the quarter car test rig is constant. The $5 \mathrm{~cm}$ elevation was chosen to take the average of the height of bump set by Malaysian Public Work Department (JKR) [25]. All apparatus is installed in the correct position as shown in Figure 5. The DYTRAN accelerometer sensor was chosen to record all vertical accelerate signal on the sprung mass and unsprung mass (tyre). The LMS Scadas Mobile was selected as the main medium for data acquisition. The experimental study is initially done using OEM passive damper before being replaced with the prototype. Table 3 shows the parameter of the experimental study. 


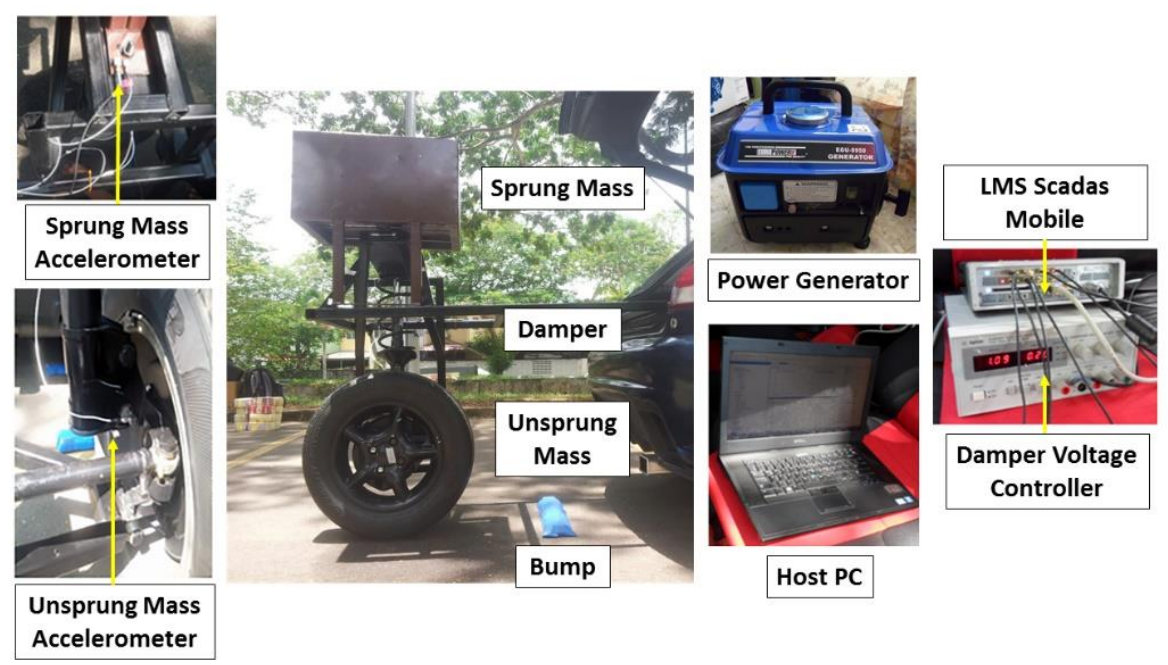

Figure 5. Working environment experimental set up.

Table 3. Parameter of C-class vehicle quarter car.

\begin{tabular}{lcc}
\hline $\begin{array}{l}\text { Vehicle } \\
\text { parameter }\end{array}$ & Value & Description \\
\hline$m_{s}$ & $250 \mathrm{~kg}$ & mass of the body \\
$m_{u}$ & $25 \mathrm{~kg}$ & mass of the tyre \\
$k_{s}$ & $17600 \mathrm{~N} / \mathrm{m}$ & spring stiffness coefficient \\
$k_{t}$ & $15000 \mathrm{~N} / \mathrm{m}$ & tyre stiffness coefficient \\
$c$ & $100 \mathrm{Ns} / \mathrm{m}$ & damping coefficient (only state for the OEM \\
& & damper) \\
\hline
\end{tabular}

\section{RESULTS AND DISCUSSION}

The finite element model simulates the magnetic flux density on the area where MR fluid is stored as demonstrated in Figure 6(a). The flux lines concentration increases as the distance between one flux lines to its adjacent become closer as displayed in Figure 6(b). Furthermore, Figure 6(c) illustrated the direction change of magnetic flux lines in vectors form once they entered the area storing MR fluid. Thus, the highest value of magnetic flux density was recorded along the area where MR fluid is stored. The average magnitude of the magnetic flux density of a particular applied current can be calculated by simply dividing the summation of the highest value and the lowest value generated in the solution by two as indicated. Linear analysis approach permits the formulation to be used. A new set of result is obtained from a new set of electric current value. The analysis is repeated by keeping the number of turns of coil constant. The results are tabulated in Table 2 and a scattered graph is plotted using MATLAB as illustrated in Figure 7(a). It can be concluded that the magnetic flux density is directly proportional to the applied current. From the data set of current magnetic flux density, a new data set of shear stress can be computed. The expression of the equation was in the form of fourth-order polynomial.

$$
\tau_{y}=6.298 B_{f}^{4}-25.824 B_{f}^{3}+26.639 B_{f}^{2}-0.438 B_{f}
$$


The equation expresses the magnetic flux density as a function of the fluid shear stress. The data set of magnetic flux density and shear stress is tabulated systematically also in Table 4 and the graph showing the relationship of those two is plotted using MATLAB and shown in Figure 7(b). The prototype control valve is capable of generating magnetic flux density greater than 1 Tesla using the selected MR fluid (MRF-122 EG 0011369535). The MR fluid has achieved its maximum shear stress and saturation has occurred when the magnetic flux density was applied beyond 0.9 Tesla as seen in the figure. Hence, any addition to the value of applied current beyond this value does not take effect. This result is critical before the semi-active damper prototype is fabricated and tested physically in the real working environment. The MR fluid is forced to flow through the magnetic active area between internal and external housing. More damping force created as the strength of the magnetic field is increased. As a pilot study, the finite element modelling results provide evidence that the semi-active damper works well in exploiting the unique properties of the MR fluid.

A root means square (RMS) of sprung mass acceleration versus frequency plot of the OEM passive damper and the MR semi-active damper prototype measured by an accelerometer is shown in Figure 8(a) to 8(d). The responses related to the passive damper and the prototype are computed by setting all the parameter in Table 3 . The amplitudes of the sprung mass acceleration were increased rapidly for the frequency range of $1 \mathrm{~Hz}$ to approximately $3 \mathrm{~Hz}$. It was noted that the value change was most obvious at around 2.5 $\mathrm{Hz}$. As it can be inferred from Figure 8(a), the performance expected from the semi-active damper on the real working environment during off-state condition has the edge over the performance of the OEM passive damper. The finding provides evidence that the presence of MR fluid alone without the influence of the magnetic field is able to offer great vibration isolation.

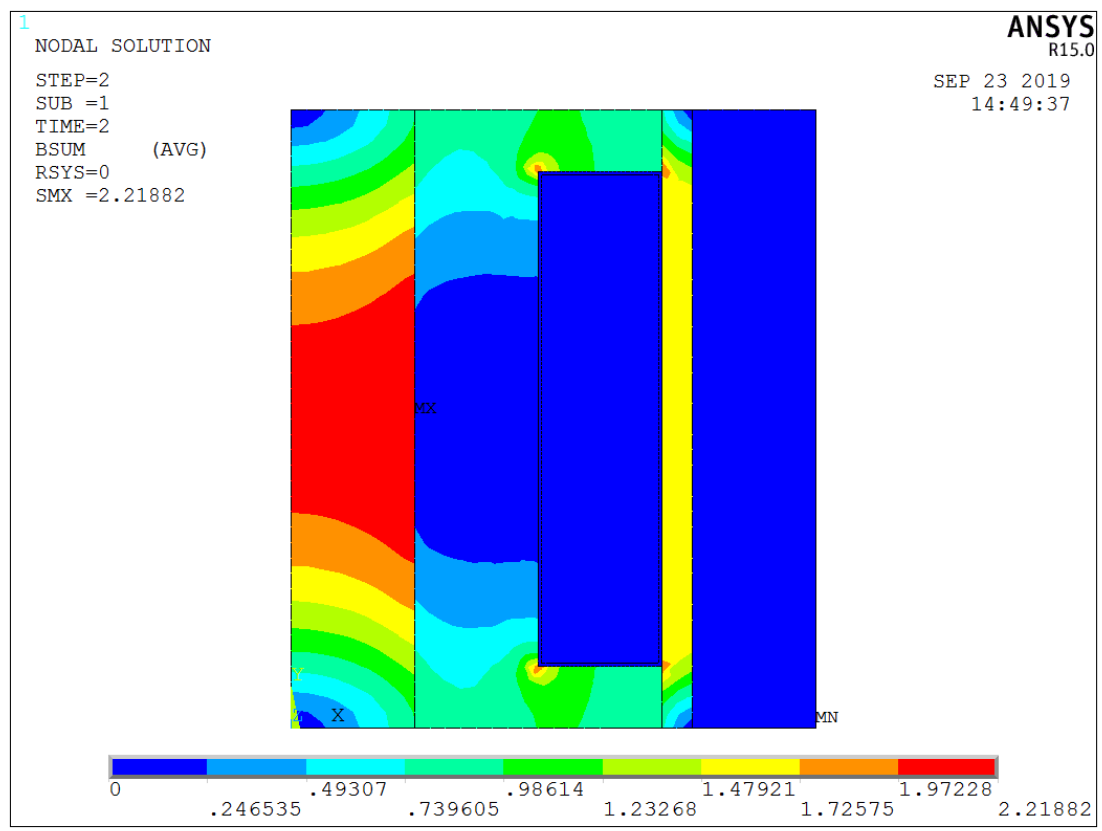

(a) 


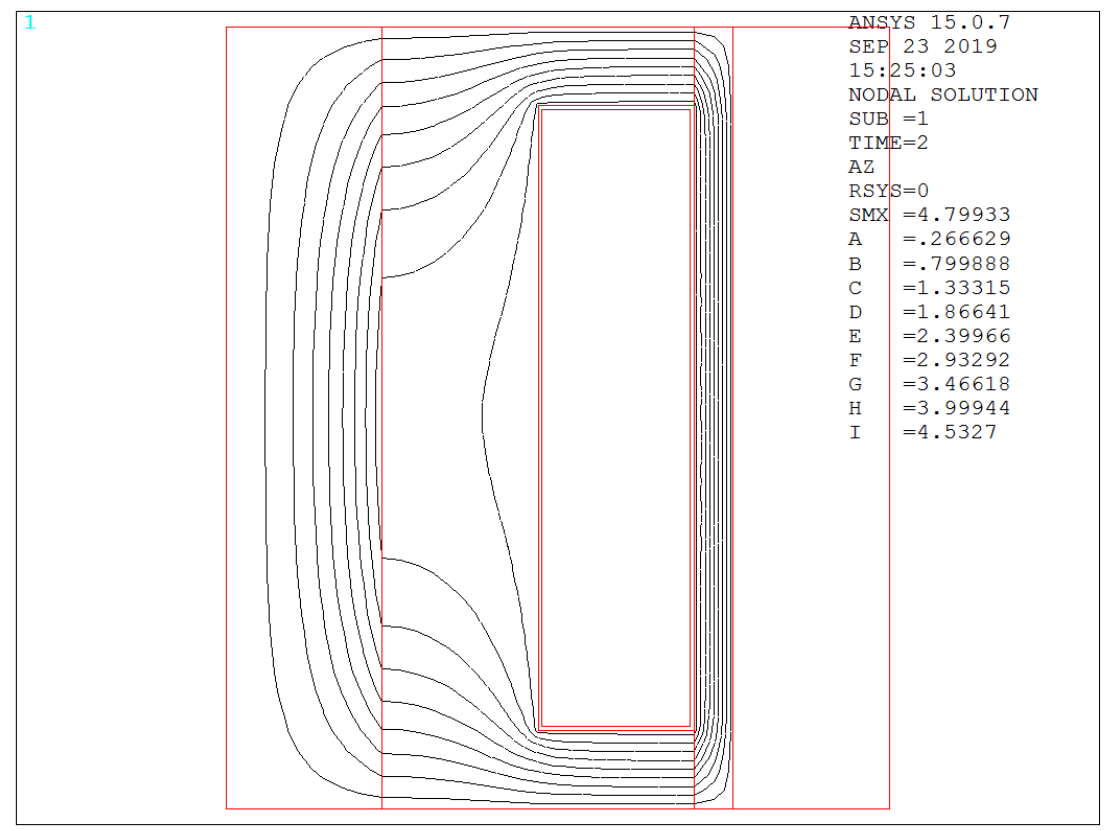

(b)

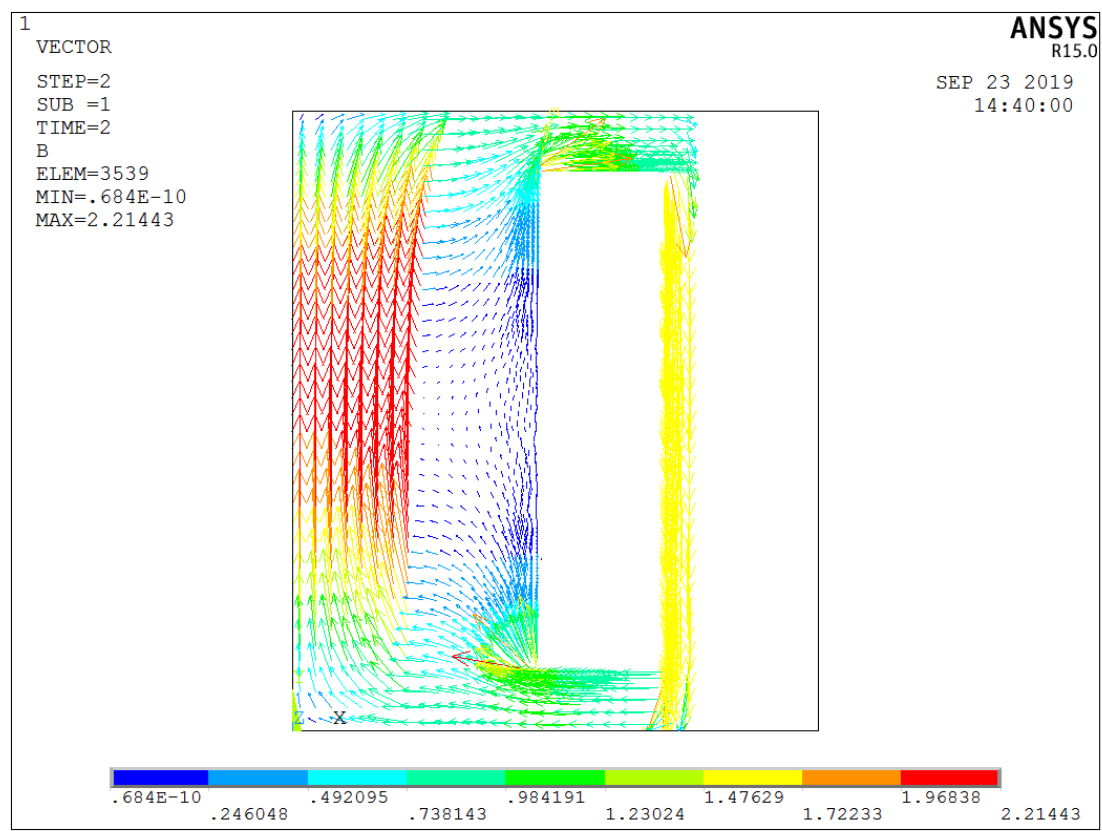

(c)

Figure 6. (a) Magnetic flux density, (b) magnetic flux line and; (c) vector form a magnetic flux line. 


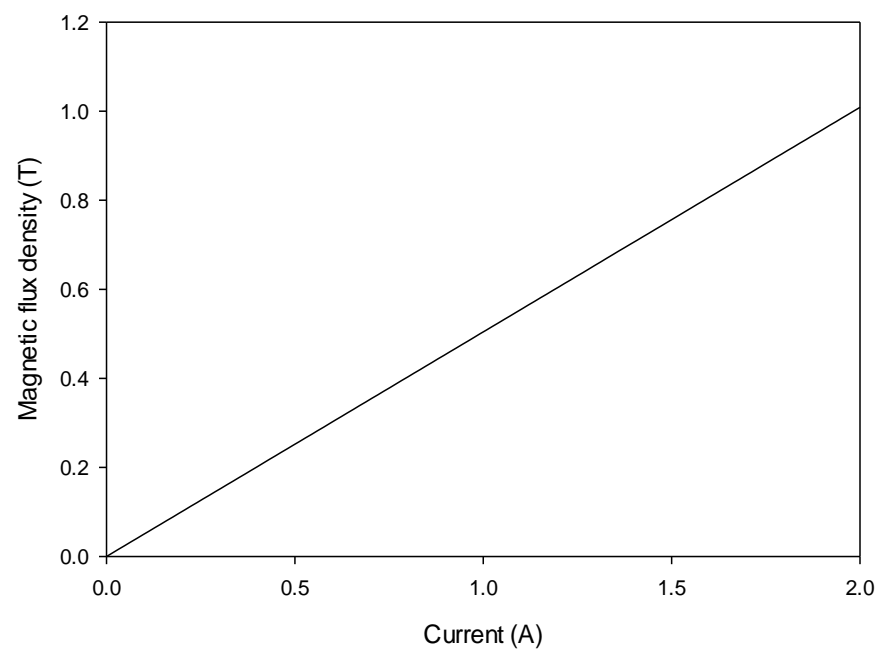

(a)

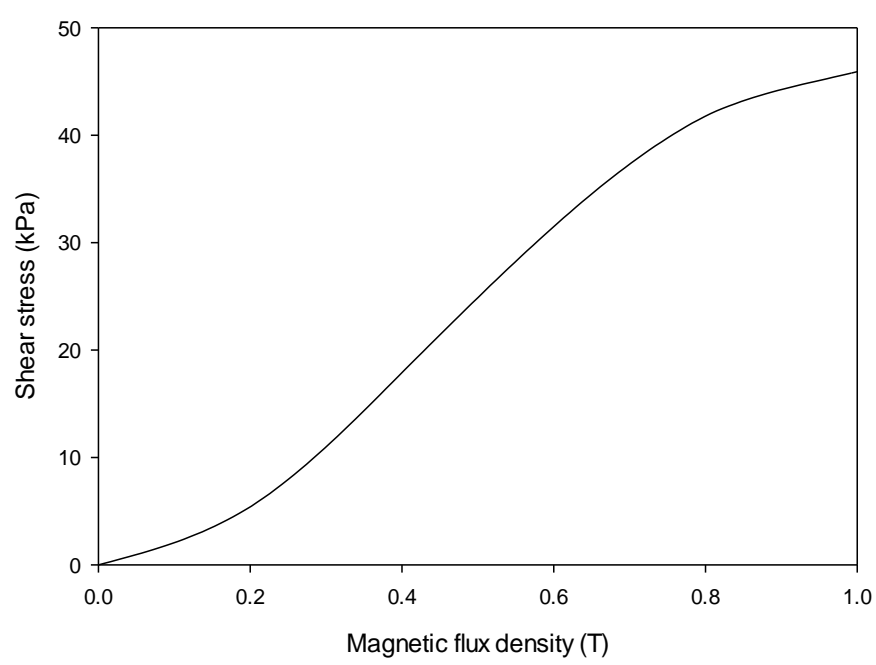

(b)

Figure 7. (a) Magnetic flux density over a variety of current and; (b) shear stress development over a variation of magnetic flux density.

Table 4. Summary of magnetic flux density and computed shear stress.

\begin{tabular}{lcc}
\hline Current (A) & Magnetic Flux Density (Tesla) & Shear stress $(\mathrm{kPa})$ \\
\hline 0.0 & 0.0000 & 0.0000 \\
0.4 & 0.2016 & 5.4691 \\
0.8 & 0.4034 & 18.1337 \\
1.2 & 0.6051 & 31.7979 \\
1.6 & 0.8068 & 42.0128 \\
2.0 & 1.0086 & 46.0490 \\
\hline
\end{tabular}

As depicted in Figure 8(a) to 8(d), the MR semi-active damper prototype information improves the ride comfort by decreasing the acceleration of the sprung mass compare to the OEM passive damper. Generally, currently applied to the semi-active damper has a fair influence on the ride comfort. The magnetic flux induced to MR fluid increases with increasing of the applied current. As discussed earlier, the higher value of 
magnetic flux caused the particle in the MR fluid aligned themselves to form a chain that resists and restrict fluid motion. Thus, promoting the development of higher yield stress. When the piston of the semi-active damper is moved due to the $5 \mathrm{~cm}$ sinusoidal bump, the MR fluids flows through the magnetic field activated area and the viscosity of the MR fluid would be changed. In this fashion, the damping characteristic varied accordingly. High damper damping values due to the rheological properties changes of MR fluid enhanced oscillatory comfort. Instead transmit the force to the sprung mass, thus encouraging discomfort, the MR fluid absorbed the vibration energy and released it in the form of heat to the surrounding which directly decreases the acceleration of the sprung mass. Moreover, the maximum temperature recorded during the experiment was not more than $40^{\circ} \mathrm{C}$. The results obtained agreed with previous simulation work carried out by Ismail and Muhamad [26].

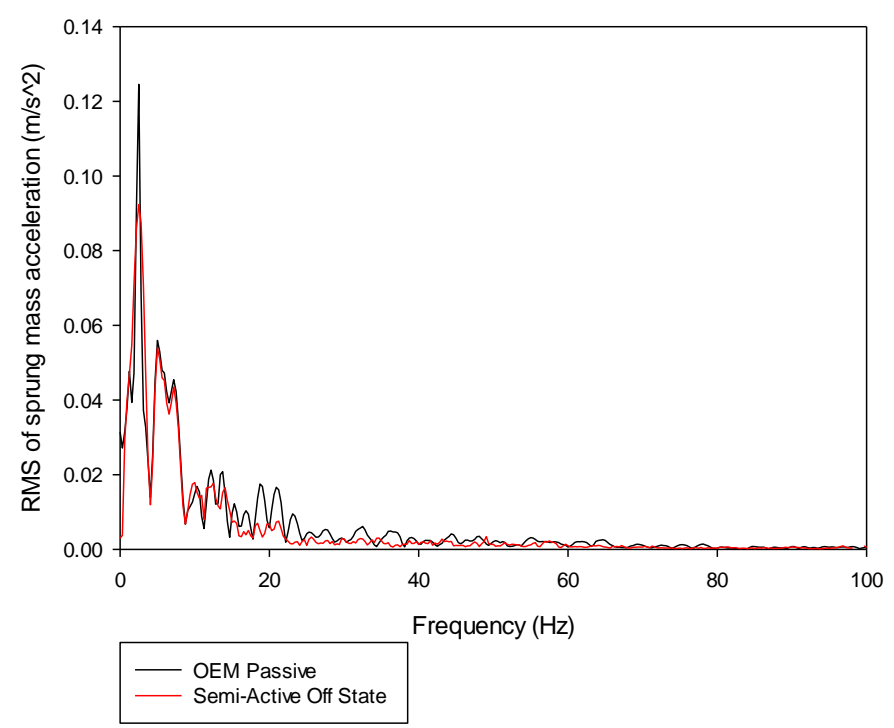

(a)

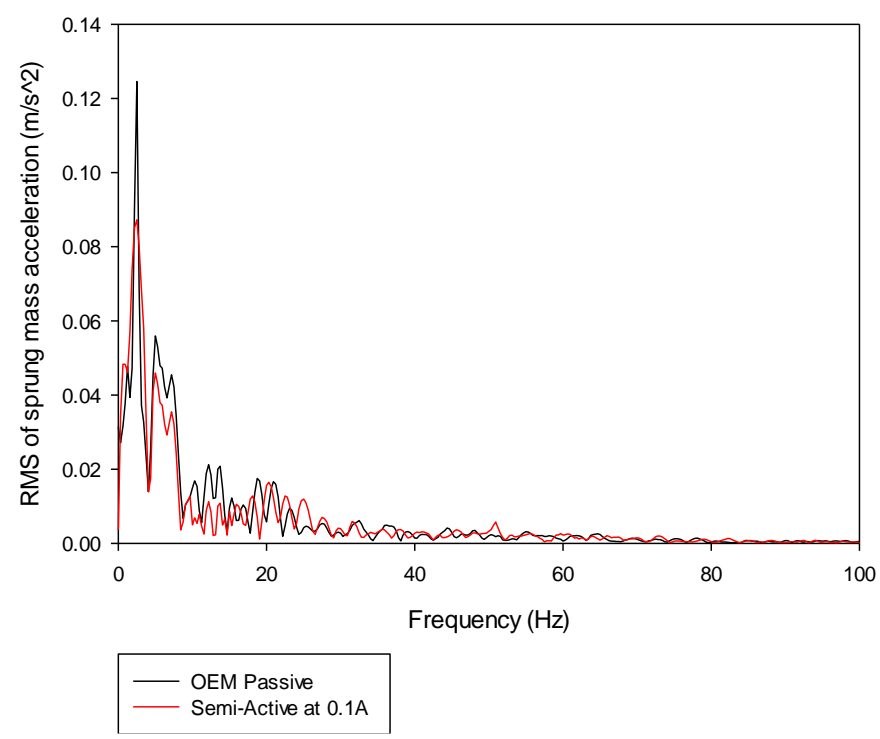

(b) 


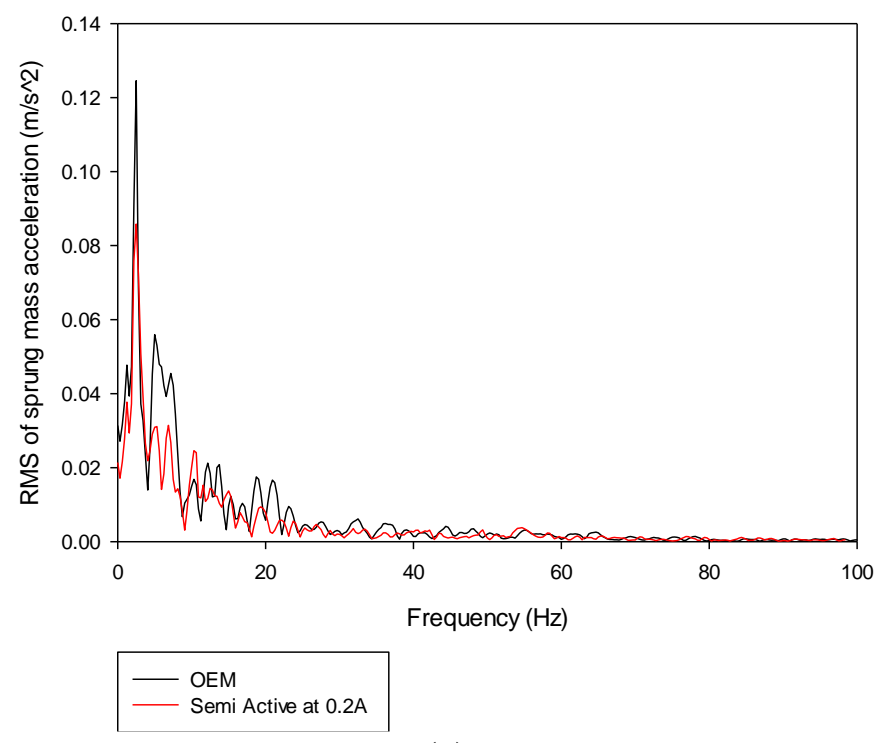

(c)

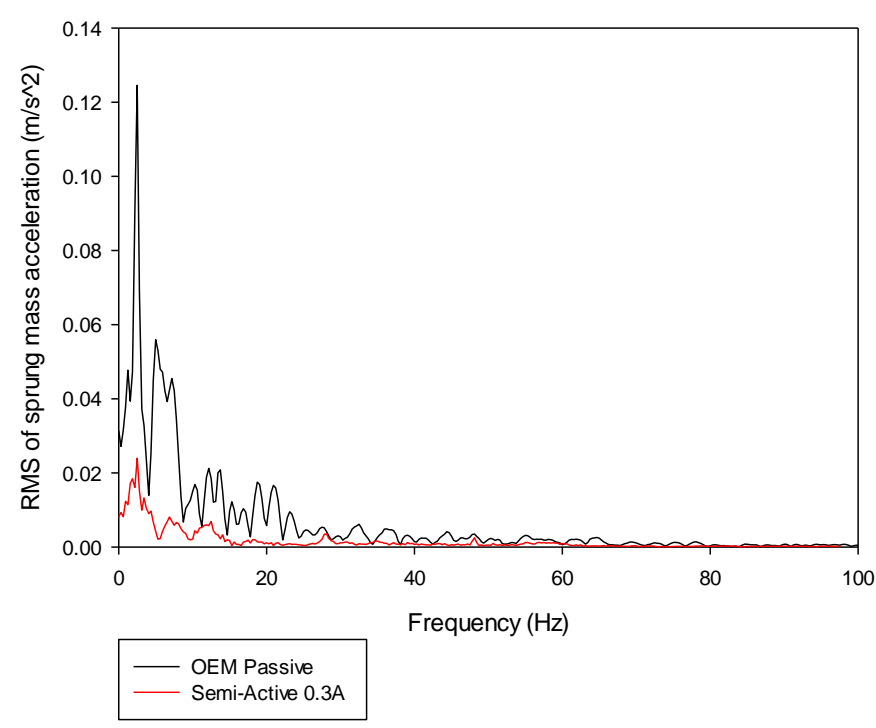

(d)

Figure 8. RMS sprung mass acceleration response of OEM passive and semi-active damper prototype at (a) offstate condition, (b) $0.1 \mathrm{~A}$, (c) $0.2 \mathrm{~A}$ and; (d) $0.3 \mathrm{~A}$.

\section{CONCLUSION}

This work was devoted to assessing the capability of the MR semi-active damper prototype with OEM technical standard for the c-class vehicle to enhance the vehicle ride comfort in a real working environment. The results of finite element modelling indicate that the design is able to induce enough magnetic field to change damping of the prototype through the application of MR fluid. An experiment was carried out to assess the proposed model prototype and comparison with OEM passive damper in term of RMS sprung mass acceleration showed that there were improvements in the ride comfort using MR fluid. It is considered that the model prototype can provide a guideline to manufacture the semiactive damper-based MR fluid considering technical standard with desired to be applied 
to the c-class vehicle. The results obtained from this study have laid an important platform from which to improve the ride comfort of the sprung mass (passenger).

\section{ACKNOWLEDGEMENT}

The writers wish to express gratitude to Malaysia Ministry of Higher Education and Universiti Teknologi Malaysia for financial support under Tier-1 Research University Grant (GUP) Project Vot No. Q.K130000.2543.19H85.

\section{REFERENCES}

[1] Tseng HE, Hrovat D. State of the art survey: Active and semi-active suspension control. Vehicle System Dynamics. 2015;53(7):1-29.

[2] Singh E, Sharma E. Suspension systems: A Review. International Research Journal of Engineering and Technology. 2017;4(4):1377-1382.

[3] Wang DH, Liao WH. Magnetorheological fluid dampers: A review of parametric modelling. Smart Materials and Structures. 2011;20(2):1-34.

[4] Dutta S, Choi SB. A nonlinear kinematic and dynamic modeling of Macpherson suspension systems with a magneto-rheological damper. Smart Materials and Structures. 2016;25(3):1-11.

[5] Amiruddin IM, Pauziah M, Aminudin A, Unuh MH. Design and development of the Macpherson Proton Preve Magneto rheological damper with PID controller. In: IOP Conference Series: Materials Science and Engineering. pp. 1-7; 2017.

[6] Paul PS, Varadarajan AS, Vasanth XA, Lawrance G. Effect of magnetic field on damping ability of magnetorheological damper during hard turning. Archives of Civil and Mechanical Engineering. 2014;14(3):433-443.

[7] Nguyen QH, Choi SB, Woo JK. Optimal design of magnetorheological fluid-based dampers for front-loaded washing machines. In: Proceedings of the Institution of Mechanical Engineers, Part C: Journal of Mechanical Engineering Science. pp. 294-306; 2014.

[8] Ashtiani M, Hashemabadi SH, Ghaffari A. A review on the magnetorheological fluid preparation and stabilization. Journal of Magnetism and Magnetic Materials. 2015;374:716-730.

[9] Kazakov YB, Morozov NA, Nesterov SA. Development of models of the magnetorheological fluid damper. Journal of Magnetism and Magnetic Materials. 2017;431:269-272.

[10] Unuh MH, Muhamad P, Norfazrina HMY, Ismail MA, Tanasta Z. Vibration isolation analysis of new design OEM damper for malaysia vehicle suspension system featuring MR fluid. In: IOP Conference Series: Materials Science and Engineering. pp. 1-9; 2018.

[11] Chongxuan K, Bo W, Shixing Z. Design and Experiment of Magnetorheological shimmy damper controller based on deep neural network. In: CSAA/IET International Conference on Aircraft Utility Systems. 2018. p. 1-6.

[12] Unuh MH, Muhamad P, Waziralilah NF, Amran MH. Characterization of vehicle smart fluid using gas chromatography-mass spectrometry ( GCMS ). Journal of Advanced Research in Fluid Mechanics and Thermal Sciences. 2019;55(2):240248.

[13] Gavin H, Hoagg J, Dobossy M. Optimal design of MR damper. In: Proc US-Japan Workshop on Smart Structures for Improved Seismic Performance in Urban 
Regions. pp. 225-236; 2001.

[14] Nguyen QH, Han YM, Choi SB, Wereley NM. Geometry optimization of MR valves constrained in a specific volume using the finite element method. Smart Materials and Structures. 2007;16(6):2242-2252.

[15] Nguyen QH, Choi SB. Optimal design of a vehicle magnetorheological damper considering the damping force and dynamic range. Smart Materials and Structures. 2009;18:1-10.

[16] Ferdaus MM, Rashid MM, Hasan MH, Rahman MA. Optimal design of magnetorheological damper comparing different configurations by finite element analysis. Journal of Mechanical Science and Technology. 2014;28(9):3667-3677.

[17] Mangal SK, Kumar A. Geometric parameter optimization of magneto-rheological damper using design of experiment technique. International Journal of Mechanical and Materials Engineering. 2015;10:1-9.

[18] Christenson R, Lin YZ, Emmons A, Bass B. Large-scale experimental verification of semiactive control through real-time hybrid simulation. Journal of Structural Engineering. 2008;134(4):522-534.

[19] Li ZC, Wang J. A gun recoil system employing a magnetorheological fluid damper. Smart Materials and Structures. 2012;21:1-10.

[20] Zhang C, Li X, Zhang S, Feng H, Zhou H, Fu Y. Design and experiment evaluation of a magneto-rheological damper for the legged robot. In: 2018 IEEE International Conference on Real-Time Computing and Robotics, RCAR 2018. pp. 687-692; 2018.

[21] Yu M, Liao CR, Chen WM, Huang SL. Study on MR semi-active suspension system and its road testing. Journal of Intelligent Material Systems and Structures. 2006;17(8):801-806.

[22] Jiang W, Zhang Y, Xuan S, Guo C, Gong X. Dimorphic magnetorheological fluid with improved rheological properties. Journal of Magnetism and Magnetic Materials. 2011;323(24):3246-3250.

[23] Togun H, Abdulrazzaq T, Kazi SN, Badarudin A, Kadhum AAH, Sadeghinezhad E. A review of studies on forced, natural and mixed heat transfer to fluid and nanofluid flow in an annular passage. Renewable and Sustainable Energy Reviews. 2014;39:835-856.

[24] Kasprzyk J, Wyrwał J, Krauze P. Automotive MR damper modeling for semiactive vibration control. In: IEEE/ASME International Conference on Advanced Intelligent Mechatronics, AIM. pp. 500-505; 2014.

[25] LORD Corporation. LORD technical data: MRF-122EG Magneto-rheological fluid. north carolina; 2019. Retrieved from: http://www.lord.com

[26] Baharuddin AR, editor. Manual fasiliti keselamatan jalan. Cetakan Pe. Cawangan Kejuruteraan Jalan \& Geoteknik, Jabatan Kerja Raya Malaysia; 2014.

[27] Ismail MA, Muhamad P, Abu A. Modelling behaviour for magneto rheological motorcycle suspension system. Applied Mechanics and Materials. 2014;663:690694. 